\title{
Neurosurgery value and quality in the context of the Affordable Care Act: a policy perspective
}

\author{
Richard P. Menger, MD, ${ }^{1,2}$ Bharat Guthikonda, MD, ${ }^{1}$ Christopher M. Storey, MD, PhD, ${ }^{1}$ \\ Anil Nanda, MD, MPH, ${ }^{1}$ Matthew McGirt, MD, ${ }^{3}$ and Anthony Asher, MD ${ }^{3}$ \\ 1Department of Neurosurgery, Louisiana State University of Health Sciences, Shreveport, Louisiana; ${ }^{2 H a r v a r d ~ U n i v e r s i t y ~ J o h n ~ F . ~}$ \\ Kennedy School of Government, Cambridge, Massachusetts; and ${ }^{3}$ Carolina Neurosurgery \& Spine Associates and Neuroscience \\ Institute, Carolinas Healthcare System, Charlotte, North Carolina
}

\begin{abstract}
Neurosurgeons provide direct individualized care to patients. However, the majority of regulations affecting the relative value of patient-related care are drafted by policy experts whose focus is typically system- and population-based. A central, prospectively gathered, national outcomes-related database serves as neurosurgery's best opportunity to bring patient-centered outcomes to the policy arena.

In this study the authors analyze the impact of the Affordable Care Act (ACA) on the determination of quality and value in neurosurgery care through the scope, language, and terminology of policy experts. The methods by which the ACA came into law and the subsequent quality implications this legislation has for neurosurgery will be discussed. The necessity of neurosurgical patient-oriented clinical registries will be discussed in the context of imminent and dramatic reforms related to medical cost containment.

In the policy debate moving forward, the strength of neurosurgery's argument will rest on data, unity, and proactiveness. The National Neurosurgery Quality and Outcomes Database (N2QOD) allows neurosurgeons to generate objective data on specialty-specific value and quality determinations; it allows neurosurgeons to bring the patient-physician interaction to the policy debate.
\end{abstract}

http://thejns.org/doi/abs/10.3171/2015.9.FOCUS15376

KEY WORDS Affordable Care Act; health care economics; health care reform; Medicaid; National Neurosurgery Quality and Outcomes Database; outcomes research

$\mathrm{T}$ HE Affordable Care Act (ACA) represents a direct and aggressive expansion of government-controlled health care delivery. This legislation will ultimately lead to wide-ranging governmental oversight and determination of health care value (i.e., quality and cost). ${ }^{24}$ According to the Kaiser Family Foundation, 270 million (of 313 million total) Americans have health insurance. Fifty-four percent have private insurance; public insurance is roughly split between Medicare (46 million, or $15 \%$ ), Medicaid (49 million, or 16\%), and "other" public insurance $(2 \%)$. Thirteen percent have no insurance. ${ }^{19}$ However, the Center for Medicare and Medicaid Services (CMS) projects that by the end of the decade 140 million individuals will be enrolled in government-run health care programs. ${ }^{6}$ Furthermore, public health care policies are rapidly being adopted in various forms by private insurers. In this environment, neurosurgery and other medical specialties must therefore endeavor to quantify the value of the services they provide within the expanding framework of national health care reform.

Neurosurgical quality and value is typically defined through a physician-patient-centered framework, with rigorous scientific testing of quality-based outcomes. However, the majority of policy applicable to the relative value of neurosurgical procedures is created by policy experts outside of our specialty who consider neurosurgery within the larger context of a vast and often cumbersome health care delivery system. Neurosurgeons need to understand the context in which those policies are formulated to effect relevant change in the evolving value-based care paradigm.

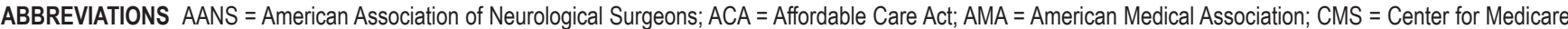
and Medicaid Services; N2QOD = National Neurosurgery Quality and Outcomes Database; PhRMA = Pharmaceutical Research and Manufacturers of America; PQRS = Physician Quality Reporting System; QCDR = qualified clinical data registry.

SUBMITTED August 1, 2015. ACCEPTED September 18, 2015.

INCLUDE WHEN CITING DOI: 10.3171/2015.9.FOCUS15376. 


\section{The Relevance of the ACA to Neurosurgeons: Policy Development}

The political formation of the ACA puts a perverse twist on quality and value, highlighting even further the need for a single, fact-driven, patient-centered neurosurgery voice. It's important for the neurosurgeon to understand the process by which the ACA developed to understand the political realities in which the policy affecting their employment was created.

The intent of the ACA is to provide affordable insurance to all Americans by increasing Medicaid coverage, by providing government support for the individual purchase of private insurance in federal or state marketplaces, by holding insurance companies accountable for the quality of coverage, and by eliminating insurance loopholes (preexisting conditions, disaster coverage, and so on). ${ }^{22} \mathrm{To}$ dilute the insurance risk pool, an individual mandate ensures that all people regardless of their health status are economically (tax penalty) incentivized to purchase health insurance. ${ }^{9}$ Individuals with an income of up to $400 \%$ of the federal poverty level may receive governmental assistance to purchase private health care. ${ }^{9}$ The employer mandate requires that all companies with more than 50 full-time employees (30 hours/week) provide insurance to 95\% of their employees by 2016 (previously delayed) or face economic penalties. ${ }^{15}$ There is no frank "Obamacare" public insurance option. The ACA is largely modeled after the 2006 Massachusetts Romney-care system, and used the same de facto architect, Massachusetts Institute of Technology economist John Gruber. ${ }^{8}$

This represents a dramatic change to one-sixth of the US economy, and it therefore ignited a firestorm of lobbyist activity on behalf of each special interest within health care. From March to April 2009, pharmaceutical companies, device companies, hospitals, and physicians groups lobbied for their interests to the Senate Finance Committee chaired by Senator Max Baucus (D-MT). ${ }^{8}$ The plot was simple; lobbyist groups were eager to barter on behalf of their constituent organizations to ensure further progress of their special interest needs during reform. Lobbyist groups representing health care special interests spent \$263 million dollars during the first half of 2009 to influence legislation. ${ }^{10}$ From 2003-2008 Senator Max Baucus alone received 3 million dollars from health care-related industries.

The equation for reform was not rooted in a determination of Value $=$ Quality/Cost. It did not focus on technical efficiency, cost-effectiveness, or allocative efficiency. Rather it was a political tradeoff; major health care groups would publicly support the ACA if concessions were made to their special interests. The goal was to avoid more substantial reform and to maintain profit margins. ${ }^{8}$ Neurosurgeons were held relatively voiceless-even the American Medical Association (AMA) did not represent neurosurgery's position. Politics determined US health care policy.

\section{Pharmaceutical Companies}

The pharmaceutical companies spent $\$ 134$ million in the first 6 months of 2009 lobbying for their position. ${ }^{10}$ It was estimated that pharmaceutical companies stood to gain at least $\$ 200$ billion in new business from the ACA, due to the expansion of coverage over the next 10-year period. ${ }^{8}$ In negotiations, the Senate Finance Committee countered by asking for a reported $\$ 130$ billion "refund" in the form of taxes and reductions in drug prices. ${ }^{8}$

In 2003, Congress passed legislation essentially prohibiting Medicare from bargaining against drug companies on prices through its Part D program. ${ }^{8,14}$ Pharmaceutical companies must receive $106 \%$ of the average drug wholesale price from Medicare. This costs the system approximately $\$ 40$ billion a year. $^{8}$ The main goal of the lobbyists for the Pharmaceutical Research and Manufacturers of America (PhRMA) was not to lose this income during the formation of the ACA. Pharmaceutical companies publicly supported the ACA in exchange for protection against generic medications and the continued prohibition of negotiations on Medicare drug prices. In return, the pharmaceutical companies agreed to a "refund" of $\$ 80$ billion (not the initially requested $\$ 130$ billion) in taxation and reduced prices for senior citizens. Following this agreement, PhRMA then bought ads in support of senators who voted in favor of the ACA. PhRMA also heavily financed political action committees that directly supported the ACA, such as "Health Economy Now" or "Americans for Stable Quality Care"-PhRMA committed $\$ 70$ million to the latter. ${ }^{8}$

\section{Hospitals}

Roughly $75 \%$ of America's hospitals are nonprofit entities. ${ }^{8}$ Due to increased insurance coverage, the hospitals were estimated to see a rise in profits of approximately \$200-250 billion. Represented by the American Hospital Association, hospitals agreed to "return" $\$ 155$ billion of the profit in the form of performance-related penalties, readmission no pays, and an acceptance of the stagnation in hospital-based Medicare reimbursement rates. A portion of the hospital's reimbursement would be dependent on a value- and quality-related matrix.

\section{Insurance Companies}

The private insurance companies stood to gain millions of new customers supplemented by government-provided subsidies. ${ }^{8}$ In anticipation, the insurance companies' lobbyist panels were fanatical about maintaining a proper risk pool to float profit margins. Insurance lobbyists pushed for a high discrepancy in premiums between older (high usage) clients and younger (low usage) clients on the order of 5:1. The American Association of Retired Persons (AARP) pushed for a 2:1 ratio, and the deal was set at $3: 10^{8,21}$ The insurance companies wanted stiff penalties to ensure that young people would be persuaded to buy their product. ${ }^{7}$ In 2015, this represents either $2 \%$ of household income or $\$ 325$ per person, whichever is higher. ${ }^{16}$

In response to these concessions, the insurance companies were willing to exclude the preexisting condition clause from policies. ${ }^{8}$ The anticipated insurance company resistance was also partially responsible for the abandonment of a complete public insurance option.

\section{Medical Device Companies}

The medical device companies were represented by the 
Advanced Medical Technology Association. ${ }^{8}$ This represented a unique situation because the hospitals and physicians were largely responsible for negotiating specific medical device fees. With that being the case, the Senate Finance Committee did not directly bargain with medical device companies in the ways previously described. However, it was deemed that the device companies had to "pay their part." From 1990 to 2010, Medtronic's compounded annual return was $14.95 \%$ (\$100 in 1990 was worth $\$ 1622$ in 2010). In response to such strong profit margins, the Senate Finance Committee presented $\$ 60$ billion in the form of a medical device tax.

\section{Physicians}

Physicians were represented by the AMA. Americans valued a choice of doctors, yet the policy team specifically wanted to narrow physician networks to control cost and reduce competition. The AMA publicly supported the ACA.$^{8}$ In return for their support, doctors were promised a repeal of the sustainable growth rate (SGR) as a legislative priority. Indeed, on March 26, 2015, the House repealed the SGR-delay had occurred in 2010 because of budget constraints.

No substantial medical malpractice reform was entertained, due to the recommendations of President Obama's policy team and Deputy Chief of Staff for Policy Nancy Ann Deparle. ${ }^{8}$ The economic team headed by Peter Orszag and Lawrence Summers recommended malpractice reform. The Congressional Budget Office estimated that this would result in $\$ 57$ billion in government savings from 2014 to 2023.12 The American Association for Justice (formerly the American Trial Lawyers Association) lobbied against tort reform.

The key hurdle for physicians was lack of unity; representation for physicians was not as uniform as in other groups. Only approximately $17 \%$ of practicing physicians are members of the AMA. ${ }^{25}$ It's worth mentioning that the AMA controls the Current Procedural Terminology (CPT) codes and, through its relationship with Medicare (government), generates a profit of \$70-\$100 million annually from its coding monopoly. The unfortunate reality of this coding structure is that physicians are competing with other physicians for the value of their services within a fixed budget pool. This was not addressed in reform.

\section{Implications for Neurosurgery}

It is critical that neurosurgeons have an active awareness of the unique challenges and opportunities they have within health care policy reform. On the one hand their voice is small. Medicare payments totaled \$583 billion in 2013, and only $12 \%$ went to physician payments. ${ }^{18}$ The American Association of Neurological Surgeons (AANS) lists only 3727 active practicing neurosurgeons. ${ }^{1}$ As a point of reference, the American Board of Internal Medicine certified 7439 new internists in 2014 and 28,528 since $2010 .^{2}$ The AARP boasts a membership of nearly 40 million people. ${ }^{23}$ As we saw with the development of the ACA, the constraints of politics will force votes on the basis of lobbying and reelection.

The AANS and the Congress of Neurological Surgeons, through the Washington Committee, did not support the ACA. They saw the ACA as increasing the federal government's role in health care without adequately addressing problems within the system. ${ }^{1}$ This represents the strong collective voice of all doctors who treat surgical diseases of the nervous system. A very small group of individuals has the ability to drive a specific but vitally important health care service in a unified way. In economics terms, it could be said that neurosurgeons have made the demand for neurological surgery very inelastic. Neurosurgeons have the monopoly on providing neurosurgery. If hospitals want to hire a neurosurgeon they must hire someone who has completed a neurosurgery residency. Neurosurgeons can use this market power to barter with larger, more powerful organizations and lobbyists on behalf of their patients.

In health care reform, big interests seemingly compete for a "piece" of a relatively capped "pie"; the government health care budget. Understanding the policy development of the ACA places emphasis on the hurdles physicians face in lobbying on behalf of their patients. These challenges will only grow stronger as the full effect of health care reform takes place. Expanding on the Neurosurgery Political Action Committee, neurosurgeons must continue to have a united front to best serve patient interests; the quality of this voice is rooted in patient data.

\section{The Relevance of National Registries in Health Care Policy: the N²OD}

Neurosurgeons need to make outcomes, quality, and value a top priority because if we cannot provide our own metrics another organization will create them for us. Indeed, the ACA has budgeted $\$ 75$ million over 5 years to develop outcome metrics. ${ }^{17}$ Beginning in 2013, the ACA dictated that hospital diagnosis-related group reimbursement would be altered $1 \%$ based on value-incentive payment increases. This will be increased up to $2 \%$ in 2017. The CMS will be modifying reimbursement by $1.5 \%$ based on patient survey Hospital Consumer Assessment of Healthcare Providers and Systems (HCAHPS) (hospital survey) scores. ${ }^{22}$ Yet, many of these health care quality improvement initiatives are not physician initiated. ${ }^{4}$

The National Neurosurgery Quality and Outcomes Database ( $\left.\mathrm{N}^{2} \mathrm{QOD}\right)$ allows direct patient-centered outcomes data to define quality in an era of booming technology but economic unsustainability. ${ }^{4}$ This prospective national database will help neurosurgeons concretely, accurately, and directly collect patient-specific data that can then be used to deliver the best possible care to our patients in the most economically viable way. These data serve as the critical tool neurosurgeons may use to provide independent, objective, fact-based evidence in the policy arguments surrounding health care.

The goal of all neurosurgeons and physicians is the open interpretation of properly recorded and analyzed data. The $\mathrm{N}^{2} \mathrm{QOD}$ (http://www.neuropoint.org/NPA\%20 N2QOD.html) allows for a better and truer representation of neurosurgery quality and value by use of a patientcentered national registry. It establishes risk-adjusted national benchmarks. It allows practice groups to evaluate their own morbidity and clinical outcomes. It allows for 
an analysis of quality and comparative effectiveness for neurosurgical procedures. ${ }^{23}$

The unique application of this data collection from the policy perspective is that it brings the individual patientphysician relationship to the policy arena. Previous systems of quality improvement are generated from claimsbased data, ignoring clinical diagnosis by focusing only on the type of services provided. ${ }^{4}$ The $\mathrm{N}^{2} \mathrm{QOD}$ allows the patient to enter the policy debate by shifting away from broad administrative datasets to individual clinical scenarios across multiple providers in multiple locations. This is a much more accurate reflection of specialty outcome quality data than Medicare's generic Physician Quality Reporting System (PQRS).

The very concept of a qualified clinical data registry (QCDR) arose to allow specialty groups more latitude in creating specific, proven, relevant quality measures for their respective fields. The $\mathrm{N}^{2} \mathrm{QOD}$ is neurosurgery's first specialty-specific QCDR. Essentially, the $\mathrm{N}^{2} \mathrm{QOD}$ functions as a much more accurate substitute for the PQRS in the determination of neurosurgery quality. The $\mathrm{N}^{2} \mathrm{QOD}$ tracks clinical data outcomes and quality for both patient and surgery. This gives neurosurgeons the power to influence their own quality incentives by providing objective information in determining their quality metrics.

From a policy perspective, the generation and control of accurate information wins debates. In 2013 Asher et al. illustrated the example of the national database generated by the Society of Thoracic Surgeons. This registry provides superbly detailed, risk-adjusted national data. In doing so, it allows thoracic surgeons to develop their own surgeongenerated performance standards. ${ }^{4}$ These standards are realistic, patient focused, outcome driven, and improve patient care. The registry provides thoracic surgeons with a single unified voice rallying around objective, prospectively collected, real-time data. Subsequently, arguments pertaining to reimbursement have also been made. ${ }^{4}$

Neurosurgeons can ensure the best quality outcomes for our patients by focusing on proper quality measurements that are meaningful. There are multiple players in health care reform, but physicians have the privilege of providing insight from individual and personal interactions with patients. The $\mathrm{N}^{2} \mathrm{QOD}$ allows neurosurgeons to bring these experiences, in a systematically collected fashion, to the discussion table.

\section{The Relevance of National Registries in Cost Containment: the $\mathrm{N}^{2} \mathrm{QOD}$}

Neurosurgery's involvement in quality determination will be critical because cost containment has yet to be fully addressed in health care reform; it's coming. The system cannot sustain itself. The Congressional Budget Office notes that if the health care laws remain generally unchanged, public debt will exceed gross domestic product in $2040 .{ }^{8}$ The emphasis on ignoring cost reform was a tactical decision made by Obama's team because fully embracing both cost and access reform was not politically viable. It represented the conflict between the policy arm and the economic advisors to the president. The Obama administration's first link to "value" focused on the dis- ruption of inequality through a government solution and governmental supplementation of a private solution. In doing so, the ACA placed more patients into an already stressed and somewhat broken system; the ACA has seen a dramatic proportional increase in Medicaid enrollment. ${ }^{5,6}$

Clinical databases are essential in this context to ensure that the true value of neurosurgery is appropriately measured and integrated into policy. Public policy makers will look to targeted data to make decisions for qualityrelated cost containment decisions. Again, generic PQRS criteria are not appropriately equipped to deal with surgical subspecialty care delivery. ${ }^{7}$ Centralized CMS quality directives will not properly represent neurosurgery quality and value, yet policy makers will be forced to act on the best available information. The $\mathrm{N}^{2} \mathrm{QOD}$ allows the neurosurgeon to stay active and relevant in the discussion by providing appropriate data for outcome, process, and structural measurements.

A thought among policy experts is that government reform of health care will create an eventual two-tier system-government supplementation and those with private insurance. This will muddle quality assessment moving forward. Those with government insurance could have worse outcomes. ${ }^{5}$ The critical application of $\mathrm{N}^{2} \mathrm{QOD}$ is that these data will be independently analyzed for risk-adjusted, patient-centered outcomes. This will portray accurate, specialty-specific information about the patient population served, based directly on actual clinical outcomes.

\section{Limitations of Procedure-Based National Registries in Policy Determination: the $\mathrm{N}^{2} \mathrm{QOD}$}

The $\mathrm{N}^{2} \mathrm{QOD}$ is a procedure-based registry. ${ }^{3}$ It focuses on establishing quality and value among neurosurgeons for neurosurgical procedures. The $\mathrm{N}^{2} \mathrm{QOD}$ does not focus on the evaluation of treatment options other than surgery. It does not investigate alternatives to neurosurgical procedures for a given disease process. Conservative options such as nonoperative care, steroid injections, or different interventions for a particular disease are not indexed and followed.

This is an important distinction because any evaluation of a treatment for a particular disease will focus on the opportunity cost as compared with the next best treatment alternative for that particular disease. The health care budget is a limited entity. Every decision about value or reform represents a tradeoff with one opportunity of care substituted for another. ${ }^{20}$ In the upcoming years, neurosurgeons will be forced to demonstrate value compared with the next best alternative in outcome measures, process measures, and structural measures for a specific disease (back pain, acoustic neuromas, neck pain, and so on). Specialty-specific quality measurements allow neurosurgeons to demonstrate value and provide transparency by providing one unified, objective, data-driven consensus opinion.

The comparative effectiveness application of the $\mathrm{N}^{2} \mathrm{QOD}$ is vitally important in this context. The $\mathrm{N}^{2} \mathrm{QOD}$ gives neurosurgeons the ability to compare different surgical procedures across the same radiographic and disease processes. This will empower the neurosurgical commu- 
nity to demonstrate the best possible surgical option regarding a specific disease entity. This consensus information can then be directly compared with conservative or alternative therapies from other data sources. This allows for an appropriate comparison of the best possible surgical option to conservative therapy in any multispecialty interdisciplinary health care cost containment and quality comparison.

The $\mathrm{N}^{2} \mathrm{QOD}$ does not provide direct data about cost or health care utilization. However, the $\mathrm{N}^{2} \mathrm{QOD}$ does allow physicians to view factors associated with individual outcomes. This allows neurosurgeons to select patients for the surgical option that will maximize the quality outcome of surgery and reduce uncertainty about variables correlated with poor outcome and increased cost. ${ }^{3}$ As quality metrics are driven forward this will be used to determine the most cost-effective, outcome-focused application of neurosurgical procedures. ${ }^{3}$

Logistically, there is cost associated with data entry and management on the $\mathrm{N}^{2} \mathrm{QOD}$ platform. A registration fee is required. Time and effort are spent in enrollment and participation. This includes patient discussion. ${ }^{3}$ In regard to this, it is stressed that the CMS requires quality measurement of some kind, and in this context the $\mathrm{N}^{2} \mathrm{QOD}$ is neurosurgery's only specialty-specific database. However, other options besides the $\mathrm{N}^{2} \mathrm{QOD}$ exist to meet government requirements.

\section{Other Registry Considerations in Policy Determination}

The overarching goal of physician-driven data collection should be a fluid communication of interregistry information to improve patient care. The $\mathrm{N}^{2} \mathrm{QOD}$ is just one tool in the toolbox. As of June 2015 there are more than 50 QCDRs that report to the CMS. ${ }^{11}$ These represent opportunities for a cross-pollination of data that can benefit neurosurgical patients. For example, information about bone quality from the National Osteoporosis Foundation's National Bone Health Alliance Quality and Improvement Registry can be integrated into spinal fusion outcomes. ${ }^{11}$ The Outcomes Based Electronic Research Database (OBERD) QCDR is an orthopedic registry with an emphasis on mental health and shared decision making in spine patients. The Quantum Clinical Navigation System (http://www.quantumcns. $\mathrm{com} /$ ) is an anesthesia database that provides information about surgical cancellations as well as intraoperative and perioperative decisions that can affect outcome. Although these databases are nonneurosurgical, each has opportunities to benefit neurosurgical patients.

Ultimately, the future of health care reform from a policy perspective will require a more integrative approach than a neurosurgery-specific procedural registry. Again, in the future, the focus will be on the most cost- and valueeffective treatment for a specific disease entity. Spinal registries that integrate conservative ancillary nonoperative treatments, pain management techniques, orthopedic outcomes, and neurosurgery outcomes will present the most comprehensive data set for policy makers.

This diagnosis-related outcomes database (as opposed to a procedure-related database) is gaining traction through the North American Spine Society (NASS). The NASS Registry (https://www.spine.org/ResearchClinicalCare/ Research/SpineRegistry.aspx) concept focuses on patientrelated characteristics of diagnosis. ${ }^{13}$ Its development targets an easy-to-use, web-based technology platform to collect data. Its goal is to incorporate a multicenter interdisciplinary approach, with both medical and surgical providers. This will be a powerful tool for neurosurgeons and orthopedic spine surgeons.

On the other end of the spectrum, there are also disease-specific and cohort-specific registries. Each provides focused information for neurosurgeons. The AO Spine Non-Fusion Registry (http://www.nonfusionregistry.com/ NFRRegistry.php) focuses on outcomes of nonfusion surgery for patients specifically diagnosed with degenerative disc disease. The Scoliosis Outcomes Database Registry (http://www.med.nyu.edu/mrc/clinical-trials/spine/ scoliosis-outcomes-database-registry) tracks trends in a specific group of subjects-patients under the age of 20 years who are surgical candidates for idiopathic scoliosis. Conversely, the Society for Minimally Invasive Spine Surgery (SMISS) launched the SMISS Registry (http://www. smiss.org/smiss-registry) targeting a specific technique. It tracks trends in the data for outcomes in minimally invasive procedures for degenerative, stenosis, instrumentation, and deformity cases. Each database has both direct and translational applications for neurosurgeons.

The future of data generation will rest on its interdisciplinary connectedness and its direct applicability to patients. Physicians, within their practice, will need to have the ability to track patient outcomes based on surgical and nonsurgical interventions, implant and hardware data, as well as patient selection criteria. The $\mathrm{N}^{2} \mathrm{QOD}$ focuses on neurosurgical procedures and will be complementary and necessary in this process.

\section{Conclusions}

The fundamental difference between health care application at the macro (policy) and micro (patient) level is ideological. Health care, at its core, is an individual, personal relationship between the patient and the provider. Outcomes on a person-by-person scale dramatically impact that individual's quality of life. An individual with a life-threatening aneurysm will not be contemplating the corresponding value of bimodal aneurysm treatment; quality will rest in the outcome for the individual. ${ }^{8}$ Policy analysts, however, must integrate multiple different players, population cohorts, and economic applications. The overwhelming majority of policy analysts are not physicians providing individualized patient-centered care, yet policy experts and politicians are the ones responsible for determining the rationing of health care expenditure. It is important to remember that physicians are the face of patient care, and that the cost of health care to the patient has and will always be largely attributed to the physicianpatient encounter.

In the policy debate moving forward, the strength of neurosurgery's argument will rest on data, unity, and proactiveness. A central, prospectively gathered, national outcomes-related database serves as neurosurgery's bridge 
to bring patient-centered outcomes to the policy arena. It serves as a tool for neurosurgeons to demonstrate qualityrelated outcomes in a culture that will be further driven by some variation of the quality, value, and cost equation.

\section{References}

1. American Association of Neurological Surgeons: Neurosurgery and Healthcare Reform. (http://www.aans. org/Legislative \%20Activities/Neurosurgery\%20and\%20 Healthcare\%20Reform.aspx) [Accessed October 15, 2015]

2. American Board of Internal Medicine: Number of Candidates Certified Annually by the American Board of Internal Medicine. (http://www.abim.org/pdf/datacandidates-certified/Number-Certified-Annually.pdf) [Accessed October 15, 2015]

3. Asher A, McGirt M, Speroff T, Gottesman J, Craig K: The National Neurosurgery Quality and Outcomes Database $\left(N^{2} Q O D\right)$ Project Objectives and Data Collection Guidelines V1.0. (http://www.neuropoint.org/pdf/ N2QOD\%20data\%20management $\% 20$ and $\% 20$ Project $\% 20$ Objectives\%20January\%202012\%20V\%201.0.pdf] [Accessed October 15, 2015]

4. Asher AL, McCormick PC, Selden NR, Ghogawala Z, McGirt MJ: The National Neurosurgery Quality and Outcomes Database and NeuroPoint Alliance: rationale, development, and implementation. Neurosurg Focus 34(1):E2, 2013

5. Atlas SW: The coming two-tier health system. Wall Street Journal. April 30, 2014. (http://www.wsj.com/articles/SB1 0001424052702304393704579528063516171576 ) [Accessed October 15, 2015]

6. Atlas SW: How Obamacare fails the poor and middle class. CNN.com. March 4, 2015. (http://www.cnn.com/2015/03/04/ opinion/atlas-obamacare-poor-middle-class/index.html) [Accessed October 15, 2015]

7. Berman B, Pracilio VP, Crawford A, Behm WR, Jacoby R, Nash DB, et al: Implementing the physician quality reporting system in an academic multispecialty group practice: lessons learned and policy implications. Am J Med Qual 28:464471, 2013

8. Brill S: America's Bitter Pill: Money, Politics, Back-Room Deals, and the Fight to Fix Our Broken Healthcare System. New York: Random House, 2015

9. Burdett G: Romneycare vs. Obamacare: key similarities \& differences. CBS Boston. November 13, 2013. (http://boston. cbslocal.com/2013/11/13/romneycare-vs-obamacare-keysimilarities-differences/) [Accessed October 15, 2015]

10. Cafferty J: Six lobbyists per lawmaker enough on health care? CNN.com. September 3, 2009. (http://caffertyfile.blogs. cnn.com/2009/09/03/six-lobbyists-per-lawmaker-enough-onhealth-care/) [Accessed October 15, 2015]

11. Centers for Medicare and Medicaid Services: 2015 Physician Quality Reporting System Qualified Clinical Data Registries. (https://www.cms.gov/Medicare/ Quality-Initiatives-Patient-Assessment-Instruments/PQRS/ Downloads/2015QCDRPosting.pdf.) [Accessed October 15, 2015]

12. Congressional Budget Office: Options for Reducing the Deficit: 2014 to 2023. Limit Medical Malpractice Torts. (https://www.cbo.gov/budget-options/2013/44892) [Accessed October 15, 2015]

13. Dyrda L: 10 US spine surgery registries to know. Becker's Spine Review. (http://www.beckersspine.com/spine/ item/14069-10-us-spine-surgery-registries-to-know) [Accessed October 15, 2015]

14. Editorial Board: Runaway drug prices. New York Times. May 5, 2015. (http://www.nytimes.com/2015/05/05/opinion/ runaway-drug-prices.html) [Accessed October 15, 2015]
15. Eilperin J, Goldstein A: White House delays health insurance mandate for medium-size employers until 2016. Washington Post. February 10, 2014. (http://www.washingtonpost.com/ national/health-science/white-house-delays-health-insurancemandate-for-medium-sized-employers-until-2016/2014/02/10/ ade6b344-9279-11e3-84e1-27626c5ef5fb_story.html) [Accessed October 15, 2015]

16. HealthCare.gov: Fees and exemptions: Individual mandate penalty you pay if you don't have health insurance coverage. HealthCare.gov (https://www.healthcare.gov/feesexemptions/fee-for-not-being-covered/) [Accessed October $15,2015]$

17. House of Representatives Committee on Appropriations: House Report 114-195. (https://www.congress.gov/ congressional-report/114th-congress/house-report/195/1) [Accessed October 15, 2015]

18. Kaiser Family Foundation: The Facts on Medicare Spending and Financing. (http://kff.org/medicare/ fact-sheet/medicare-spending-and-financing-fact-sheet/) [Accessed October 14, 2015]

19. Kaiser Family Foundation: Health Insurance Coverage of the Total Population. (http://kff.org/other/state-indicator/ total-population/) [Accessed October 15, 2015]

20. Mankiw G: Principles of Economics, ed 6. Mason, OH: South-Western Cengage Learning, 2011

21. Moeller P: How Obamacare will affect health insurance rates by age group. US News \& World Report. August 8, 2013. (http://money.usnews.com/money/blogs/the-bestlife/2013/08/08/how-obamacare-will-affect-health-insurancerates-by-age-group) [Accessed October 15, 2015]

22. Patient Protection and Affordable Care Act of 2010, Pub Law 111-148, 124 Stat. 127, Sec. 6301 (March 23, 2010)

23. Plumb T: AARP loses 300,000 members over health care reform debate. Washington Business Journal. April 8, 2011. (http://www.bizjournals.com/washington/printedition/2011/04/08/aarp-loses-300000-members-over-health. html) [Accessed October 14, 2015]

24. Price-Haywood EG: Clinical comparative effectiveness research through the lens of healthcare decisionmakers. Ochsner J 15:154-161, 2015

25. Scherz H: Why the AMA wants to muzzle your doctor. Wall Street Journal. May 7, 2010. (http://www.wsj.com/ articles/SB10001424052748703961104575226323909364054) [Accessed October 15, 2015]

\section{Disclosures}

The authors report no conflict of interest concerning the materials or methods used in this study or the findings specified in this paper.

\section{Author Contributions}

Conception and design: Menger, Guthikonda, Storey, McGirt, Asher. Acquisition of data: Menger. Analysis and interpretation of data: Menger, McGirt, Asher. Drafting the article: Menger, Guthikonda, Storey. Critically revising the article: Menger, Guthikonda, Storey, Asher. Reviewed submitted version of manuscript: Menger, Guthikonda, Storey, Asher. Approved the final version of the manuscript on behalf of all authors: Menger. Administrative/technical/material support: McGirt. Study supervision: Guthikonda, Nanda, Asher.

\section{Correspondence}

Richard Menger, Department of Neurosurgery, LSU Health Sciences Center-Shreveport, 1501 Kings Highway, P.O. Box 33932, Shreveport, LA 71130-3932. email: richard.menger@gmail.com. 